\title{
HOMOSSEXUALIDADE E O CONTEXTO EDUCACIONAL PARAENSE: A IMPORTÂNCIA DE POLÍTICAS PÚBLICAS ESPECÍFICAS
}

\author{
Ligia T. Lopes SIMONIAN ${ }^{1}$ \\ Núcleo de Altos Estudos AmazônicosUfPA \\ simonianl@gmail.com \\ Jasson Iran M. da CRUZ 2 \\ Secretaria de Estado da Educação do ParáPA \\ iranmonteiro@gmail.com
}

Resumo: Por meio deste paper, se discute a importância da criação e implementação de uma coordenadoria para tratar da educação de GLBT no âmbito da Secretaria de Educação do Estado do Pará. Especialmente no âmbito político, sabe-se que nesse estado os GLBT pouco persistem na educação formal, o que os fragiliza enquanto indivíduos e cidadãos. Realizou-se pesquisa documental e bibliográfica (envolvendo principalmente legislação, políticas públicas e movimentos sociais), bem como incorporou-se no trabalho materiais de pesquisas anteriores dos autores efetivados no Pará e na Amazônia. Assim, evidenciou-se não só a necessidade de

\footnotetext{
${ }^{1}$ É Ph. D. em Antropologia e tem pós-doutorado (Universidade da Cidade de Nova Iorque - CUNY, 1993, 2000); desde 1994, é professora e pesquisadora do Núcleo de Altos Estudos Amazônicos - NAEA, da Universidade Federal do Pará - UFPA (Belém, Pará), sendo atualmente Professora Associada 3. Faz pesquisa sobre políticas públicas, desenvolvimento, recursos naturais, políticas fundiárias (terras indígenas, reservas extrativistas e outras unidades de conservação), populações tradicionais, estudos sobre mulheres, gênero e outras sociabilidades, violência, cultura, dentre outros tópicos. Fez pesquisas sobre homossexualismo na Amazônia e já orientou uma dissertação de mestrado sobre travestismo e cidadania e um trabalho de conclusão de curso de graduação sobre homossexuais em contextos familiares.E-mail: simonianl@gmail.com.

${ }^{2}$ É graduado em Ciências Sociais pela UFPA e pós-graduado em Planejamento e Gestão do Desenvolvimento Regional. Pós-graduado em Planejamento Urbano e Gestão Local, por esta mesma Universidade. É professor concursado da Secretaria de Estado da Educação do Pará - SEDUC-PA e exerce a profissão na cidade de Parauapebas, neste mesmo estado. Fez pesquisa sobre homossexualidade e família na cidade de Santarém, estado do Pará. É militante da causa dos gays, lésbicas, bissexuais, travestis e transexuais -GLBT em seu estado.E-mail: iranmonteiro@gmail.com.
} 
uma política pública paraense afirmativa quanto aos GLBT, o que é essencial para o fortalecimento desses cidadãos frente a si mesmos, à sociedade e ao Estado.

Palavras-chave: Homossexualidade. Política educacional. Pará.

Abstract: Through this paper it is discussed the importance of the creation and the implementation of a Coordination to deal with GLBT education in the context the Education Secretary of the State of Para. Especially in the political sphere, it is known in such State the GLBT do not persist in formal education, which weak them as individuals and citizens. Documental and bibliographic research was done (involving mainly Law, public policies and social movements), as well as it was incorporated existing research material of the authors that were produced in Para and in the Amazon. So, it is evidenced not only the necessity of an affirmative paraense public policy to the GLBT, which is essential to the empowerment of such citizens vis-à-vis themselves, the society and the State.

Key-words: Homosexuality. Educational policy. Para.

\section{Introdução}

A questão da homossexualidade é importante em qualquer contexto sócio-cultural e certamente desde os tempos antigos. Aliás, a literatura acadêmica revela que tal realidade é inclusive disseminada na humanidade (SCHNNARCH, 1992). O mesmo pode ser dito em relação ao Brasil, pois o comportamento homossexual foi uma presença marcante entre os indígenas e, desde tempos coloniais, se tem notícias sobre a sua existência na sociedade colonial (Mott, 2002). E se em algumas sociedades, os indivíduos homossexuais são respeitados socialmente e/ou no campo da religião, em outras eles sofrem toda sorte de discriminação e mesmo violência, como no caso deste país e do estado do Pará. Nesses termos, transformações culturais, principalmente no âmbito da educação, são essenciais. Sobretudo na educação pública, que atende categorias pobres, discriminadas historicamente pelas diferenças étnico-raciais, deficiências e homossexualidade.

As relações homossexuais são construídas culturalmente e a partir de contextos históricos específicos. Por exemplo, "Na cultura ocidental, os homossexuais são definidos como pessoas que entram em relações de companheiros com seres humanos do mesmo sexo biológico, apesar 
de não mudarem seus status de gênero nem seus papéis de gênero" (SCHNNARCH, 1992, p. 348). A considerar-se esse conceito, tem-se um diferencial quanto às travestis, pois apesar de corpo masculino, elas se sentem mulher. $\mathrm{Na}$ tentativa de superar em parte essa contradição, o que elas tem feito é minimizá-la ou mesmo sublimá-la através de maquiagem e da indumentária feminina que passam a usar a partir de certa idade.

Em algumas sociedades contemporâneas, parte significativa dos indivíduos que se autoidentificam como GLBT constitui um segmento social afluente, o que tem sido propiciado em especial pela educação, pela participação em movimentos sociais e/ou na estrutura política (KLAUWITTER, 2002; SIMONIAN, 2000, 1993-1989). Isso vem ocorrendo notadamente nos Estados Unidos da América - EUA e nas metrópoles mundiais. Quanto à educação, muitos chegam ao nível da sofisticação, o que inclui o acesso a cursos de doutorado, estudos pósdoutorais, salários elevados, consumo sofisticado (COSTA, 2002; LUKENBILL, 1999; SIMONIAN, 2000, 1993-1988). Inclusive, por experiência pessoal, Simonian (2000, 1993-1988) tem observado essa realidade a partir de convivência, principalmente com gays e lésbicas ${ }^{3}$.

No Brasil, a realidade de GLBT tem sido diferente da dos EUA e bem mais próxima à vivida nos guetos desse mesmo país (FRY, 1982; PARKER, 1991; SILVA, 1993). Recentemente, inclusive, em pesquisa realizada no país, chegou-se a um resultado bruto de $99 \%$ dos entrevistados reconhecendo a existência de preconceito contra estas categorias sociais, o que, inclusive, pode sugerir que os próprios GLBT sejam também homofóbicos $(99 \%, 2009)$. Mas, segundo Gustavo Venturi, organizador e diretor da pesquisa, tal resultado precisa ser analisado melhor.

Em primeiro lugar, a pesquisa foi realizada em meados de 2008, com o objetivo de "[...] subsidiar ações para que as políticas públicas avancem em direção à eliminação da discriminação e do preconceito contra a população [GLBT], de forma a diminuir as violações de seus direitos e a promover o respeito à diversidade sexual" (VENTURI, apud NOVENTA, 2009, n. p.). E, nesse sentido, a mesma foi reveladora

\footnotetext{
${ }^{3}$ Precisamente, com homossexuais que conheceu no programa de doutoramento da universidade em que se titulou $\mathrm{Ph}$. D. em Nova Iorque e de outros conhecidos ao longo de sua vida e enquanto profissional; inclusive, alguns e algumas se transformaram em seus amigos e amigas.
} 
sobre a importância da proposição e da efetivação de políticas públicas que possam combater tal realidade. Ainda, se pode destacar nesta mesma direção as de natureza educacionais, como exemplares.

Todavia, com relação a tal resultado, a pesquisa indicou diferenciações. Por exemplo, apenas "[...] 6\% dos entrevistados foram classificados como tendo forte preconceito contra LGBT" (NOVENTA, 2009 , n. p.). Os demais $93 \%$ estão distribuídos entre os que tem preconceito mediano ou leve. E se esta diversificação quanto aos percentuais modifica a compreensão dos resultados da pesquisa, não minimiza a constatação de que a sociedade brasileira é dominantemente homofóbica e que pouco tem sido feito pelo Estado para mudar tal realidade.

Pelo que as pesquisas realizadas na Amazônia e no Pará revelam, sabe-se que há um déficit educacional enorme quanto aos GLBT (CRUZ, 2002; FERREIRA, 2003; SIMONIAN, 2004). Isso tem se refletido inclusive no nível de conhecimento quanto a sua condição emocional e sexual, notadamente quanto às travestis que muitas vezes fazem uso de silicone, até industrial, com prejuízo mesmo mortal, vindo muitas a óbito. Ainda, devido à discriminação e à violência, muitíssimos GLBT deixam os bancos escolares cedo e sequer completam o ensino fundamental. Aliás, segundo Mott (1997), até 1997, este era um dos poucos estados que não disponha de legislação própria protetora desta categoria social ${ }^{4}$.

Ressalte-se neste ponto, que o argumento que permeia as reflexões ora realizadas diz respeito à importância das políticas públicas que garantam a inserção de homossexuais no sistema educacional e em sua plenitude. E o que segue é uma discussão conceitual sobre a relação entre homossexualidade, educação e sustentabilidade. Logo, tem-se uma discussão introdutória sobre a escola, a inserção dos homossexuais no estado do Pará e a importância política de uma intervenção do Estado no sentido de garantir o direito à educação aos GLBT paraenses. E conclui-se acerca das contradições encontradas na relação sob análise e aponta-se sugestões quanto transformações sustentáveis possíveis.

${ }^{4} \mathrm{O}$ mesmo ocorria em relação a seus municípios (id., ibid.). 


\section{Aspectos conceituais - das muitas homossexualidades, de educação e de sustentabilidade}

Do ponto de vista teórico, alguns conceitos são fundamentais para a compreensão da relação ora em discussão e, notadamente, os de homossexualidade, educação e sustentabilidade. Por sua vez, estes também se remetem às problemáticas do desenvolvimento humano e do desenvolvimento sustentável. Como se observa, a pensar-se a inserção de homossexuais no sistema educacional, uma realidade muito complexa emerge nos contextos socioculturais, que por sua vez inclui a questão das representações e da violência em suas modalidades as mais diversas.

E quanto ao conceito homossexualidade, conforme já apontado anteriormente, em sua essência, o mesmo se remete a relações de companheiros entre pessoas do mesmo sexo, mas sem que o status e o gênero se alterem (SCHNNARCH, 1992). Mas para além desta definição, há de se ressaltar que os homossexuais "[...] criam uma cultura homossexual preenchida com histórias da vida homossexual, com a história da homossexualidade e com política homossexual" (PLUMMER, 1995, p. 87). E também há todo um contexto de inserção sociocultural mais amplo, no qual em geral dominam os processos de discriminação contra esta categoria social e/ou são praticados por seus integrantes contra eles mesmos.

No que se refere à questão educacional, nos tempos modernocontemporâneos, a tendência política é a da inclusão dos homossexuais ao sistema, pois são cidadãos de seus respectivos países e também do mundo. Nesta direção, se posicionam a Declaração Universal dos Direitos Humanos da Organização das Nações Unidas - ONU (Organização, 1948) e, no caso do Brasil, a Constituição (Brasil. Constituição, 1988) vigente, pois dentre outros direitos, garantem o da educação. Porém, são muitas as contradições enfrentadas pelos homossexuais ao tentarem se inserir em instituições voltadas à educação formal. E como posto por Cruz (2002), mesmo no âmbito da educação familiar, os preconceitos contra os filhos homossexuais são muitos e perturbadores das possibilidades educacionais.

Mas como pensar a problemática da sustentabilidade a partir da realidade educacional dos homossexuais? Certamente, este fenômeno 
há de implicar em condições adequadas de reprodução biológica e social dos indivíduos e dos grupos homossexuais. Até a pouco, por reprodução biológica neste contexto, a questão da saúde, em especial em face à disseminação de doenças ${ }^{5}$. Aliás, por décadas as políticas públicas buscaram salvar vidas de homossexuais infectados com o vírus HIV ou já enfermos com AIDS, e se desconsiderou em muito os processos socioculturais nos quais, em sua maioria, eles estavam inseridos, a exemplo do sistema educacional.

Entretanto, nos últimos anos, a transformação da cultura gay que vem incorporando processos e práticas políticas relacionadas a demandas por direitos, tem transformado tal realidade. Nesta perspectiva, é exemplar a inserção dos GLBT no processo de reconhecimento jurídico das uniões homossexuais e a constituição familiar a partir de casais homossexuais estão a fazer parte da discussão acerca da sustentabilidade nesta realidade social (CRUZ, 2002; OROSCO, 2004; PEDROSO, 2003; SIMONIAN, 2003; WESTON, 1991). Por sua vez, sustentabilidade implica em ir além dos interesses individuais dos homossexuais, embora estes sejam igualmente importantes.

O cruzamento destes conceitos revela contradições as mais diversas e quase todas anti-homossexuais e mesmo aquelas geradas no contexto da cultura homossexual antes referida. Por sua vez, tais contradições subsumem um vínculo intrínseco com representações construídas historicamente e envolvendo homossexuais, sendo estas de natureza religiosa, ético-moral, psicológicas, biológica e psicossocial (LACERDA, PEREIRA, CAMINO, 2002). E no âmbito da educação, todas estas perspectivas geralmente incidem nos indivíduos homossexuais e também nos grupos que se formam a partir de suas sociabilidades específicas. Mas da complexidade desta realidade, o Estado tem se mantido ausente.

\section{Homossexualidade e escola pública no Pará e a importância de uma coordenadoria especializada}

No que se refere à realidade paraense, não se conseguiu localizar pesquisas acadêmicas específicas sobre a presença GLBT nas escolas

\footnotetext{
${ }^{5}$ Em especial das Doenças Sexualmente Transmissíveis - DST e da Acquired Immunodeficiency Syndrome - AIDS.
} 
e isto independentemente do nível do estudo. De todo modo, por experiência própria de vida, e longa, com pesquisas na região, se tem um conhecimento muito próximo do que se pode caracterizar como uma realidade padrão (CRUZ, 2002; PEDROSO, 2003; SIMONIAN, 2004, 2003). E esta é certamente indicativa de aspectos positivos, mas poucos, e dominantemente de aspectos negativos, envolvendo toda sorte de preconceitos e mesmo de violência.

Por ocasião da pesquisa envolvendo homossexuais, muito se ouviu em campo sobre as trajetórias pessoais destes cidadãos e particularmente quanto às suas experiências em torno da educação formal. Uma travesti de Belém assim se manifestou a respeito, em 2004: "Não aguentei ficar na escola; a meninada esculhambava comigo. Tinha dia que era brincadeira, mas mais era agressão mesmo. Agora estou aí e nem primário [ensino fundamental] tenho" ". Um gay de Belém que conseguiu ir em frente no campo dos estudos afirmou em 2005 que teve de "engolir em seco" as humilhações e a violência no dia a dia das escolas por onde passou ${ }^{7}$. Outro de Santarém revelou que foi cortado com estilete na escola em 2007, mas que ninguém deu atenção; se sentiu intimidado e desistiu da escola. ${ }^{8}$.

A mídia em geral e a Internet têm disponibilizado muita informação sobre experiências similares de parte de GLBT sobre suas relações com o sistema educacional em termos mundiais, mas também sobre a relação entre estes e a educação formal. Aliás, a respeito, a imprensa escrita acaba de divulgar que em Altamira, uma "Menina é impedida de estudar porque é gay" (MENINA, 2009, p. 4), ${ }^{9}$ o que se coloca como paradigmático em relação à problemática em análise. Entretanto, ultimamente o movimento social entre os GLBT tem avançado e apresentado publicamente as suas demandas - dentre as quais as de natureza educacionais -, processo que

\footnotetext{
${ }^{6}$ A entrevistada pediu anonimato; informação verbal, 2004.

${ }^{7}$ Idem à nota n. 5, 2005.

${ }^{8}$ Idem à nota n. 5, 2007.

${ }^{9}$ Esta matéria jornalística traz notícia sobre a discriminação contra jovem lésbica de 17 anos, em escola particular de Altamira; outra versão apresentada é a de que a escola recusou a rematrícula da aluna por que família estava inadimplente (MENINA, 2009).
} 
se intensificou com a ampliação da correlação entre a homossexualidade e a disseminação da AIDS.

Inclusive, em meados do ano de 2008, produziu-se uma síntese das propostas de conferências estaduais (BRASIL, SECRETARIA, 2008) - uma das quais, a do Pará -, as quais tiveram por eixos temáticos os seguintes: direitos humanos, saúde, educação; justiça e segurança pública, cultura, comunicação, turismo, trabalho e emprego, previdência social, cidades e esportes. Todos eles encontram-se detalhadíssimos, inclusive o da educação. Como na maioria dos demais eixos temáticos, chegou-se a um nível de detalhamento tal que envolveu dezenas de questões ligadas à relação homossexualidade e educação.

De todo modo, insere-se a seguir apenas a primeira de todas as proposições que resultaram dessas conferências estaduais, pelo seu grau de amplitude. Veja-se:

Elaborar diretrizes que orientem o sistema de ensino público e privado na formulação e na implementação de ações (criação e/ou reelaboração de resoluções em universidades, reformas curriculares, PPP - projeto político pedagógico das escolas) que promovam o respeito e o reconhecimento da orientação sexual e identidade de gênero e que colaborem para a prevenção e a minimização da violência sexista e homofóbica na educação básica e superior (BRASIL. SECRETARIA, 2008, p. 62).

E, a ser efetivada, o que é de se esperar, e imediatamente, apenas com a implementação desta proposição, se terá certamente uma revolução cultural no país quanto à relação GLBT e educação e, portanto, também no Pará.

Ao dar-se início ao processo que tal demanda dos GLBT implica, a sociedade responderá, a começar com as associações e ONG que de algum modo trabalhou para que se chegasse às conferências recentes acima referidas. Efetivamente, no Pará já se tem avanços que por certo são fundamentais nessa direção. Por exemplo, tem o Movimento de Homossexuais de Belém - MHB, as associações Cidadania, Orgulho e Respeito - COR, Grupo Apolo e o Grupo Homossexual do Pará - GHP, e outras tantas do interior do estado, a exemplo do Grupo Homossexual 
da Transamazônica e Xingu. Ainda, esta realidade, e mesmo rede, tem se ampliado com a participação da Sociedade de Direitos Humanos do Pará - SDDH-PA, da Ordem dos Advogados dos Brasil - OAB - secção Pará e dos Ministérios Públicos - MP, quer federal quer estadual.

Neste ponto, é de se ressaltar a importância da participação das universidades e de outras Instituições de Ensino Superior - IES - em tal processo, pois até o momento seu envolvimento tem sido tímido. Mas, como as propostas dos GLBT paraenses se voltam também para a cultura e a educação, além de tantos outros aspectos, o trabalho destas instituições há de ser central em um processo novo que implique em inclusão desta categoria até o momento tão discriminada e vilipendiada em seus direitos fundamentais. Uma programação de pesquisas, debate, divulgação dos resultados destas atividades via publicações impressas e por meio de outras mídias, capacitação de professores, de funcionários, incorporação de alunos na graduação e a pós-graduação etc. são algumas das tantas atividades que requererão a presença das universidades.

Todavia, no Pará, a união dessas e de outras forças políticas lograram alterar, num sentido pró-GLBT, a Constituição do estado do Pará, isto 2003. Precisamente, produziu-se e efetivou-se a Emenda Constitucional n. 20, de 17 de junho de 2003. Consequentemente, esta Constituição dispõe que é dever do estado do Pará "[...] promover o bem de todos, sem preconceitos de origem, raça, sexo, orientação sexual [grifo dos autores], cor, idade e quaisquer outras formas de discriminação" (Pará, 2003, n. p.). Nesses termos, as bases para uma política pública já se encontram na mesa em que se decidirá por priorizar aspectos da realidade dos GLBT e de sua inserção em contexto sociocultural mais amplo, o que inclui o sistema educacional.

Note-se que esta determinação constitucional do estado Pará está sendo reformada desde 29 de janeiro p. p., com a campanha liderada pela Articulação Nacional de Travestis e Transexuais - ANTRA - e pela Associação Brasileira de Gays, Lésbicas, Bissexuais, Travestis e Transexuais - ABGLT - em prós de direitos dos Travestis. Precisamente, busca-se

[...] atingir as escolas públicas brasileiras para que respeitem a identidade de gênero de Travestis e Transexuais, essa é uma luta antiga dessas duas instituições e tomou mais força agora porque 
recentemente no dia 01/01/2009 começou a vigorar em todo o estado do Pará uma portaria (016/2008) que autoriza Travestis e Transexuais a utilizarem os nomes sociais no convívio escolar (DIA, 2009, n. p).

E "A proposta ganhou força após a Secretaria da Educação do Estado do Pará - SEDUC-PA - baixar portaria n. 016/2008, que autoriza os colégios de ensino público a utilizarem os nomes sociais das(dos) transexuais e travestis" (A articulação, 2009, n. p.). Ainda segundo essa fonte, outras organizações nacionais estão juntas nesta campanha: a Articulação Brasileira de Lésbicas - ABL, o grupo E-Jovem, Grupo de Pais e Mães Homossexuais e o Coletivo de Entidades Negras - CENBrasil.

Consequentemente, a criação de uma Coordenadoria especializada no âmbito da SEDUC-PA pode constituir-se em canal articulador/ condutor de políticas e ações voltadas à consolidação da formação dos GLBT e da sociedade paraense como um todo. O que está em jogo fundamentalmente é a questão da cidadania plena dos GLBT e - por que não? -, dessa sociedade mais ampla. Nesses termos, ganharão o estado do Pará, os GLBT e os paraenses em geral.

Embora esta proposta não tenha avançado do ponto de vista da institucionalização no governo estadual que ora finda, é de observar-se que em outras situações se avançou quanto aos direitos dos indivíduos/ cidadãos GLBT do Brasil e o mundo. Inclusive, no país, 2010 foi um ano importante nessa direção. Precisamente, como se depreende de Adoção (2010) e de Casamento (2010), respectivamente uma jurisprudência se firmou quanto ao direito de indivíduos ou casais GLBT adotarem filhos e de campanhas políticas quanto à possibilidade de casamento civil. Aliás, nesse aspecto, a problemática chegou à campanha política presidencial de modo antiglbt, pois aspectos laicos e religiosos formaram a base da discussão, se perdendo, portanto, a oportunidade de discutir tal questão nas perspectivas dos direitos e cidadania.

O conservadorismo dominante nos contextos familiar, religioso e mesmo em outras esferas sociais certamente contribuiu para que a Coordenadoria proposta e necessária no âmbito das políticas e ações públicas não viesse ser criada e implementada até o momento. De fato, como pesquisas diversas tem revelado, as famílias estão muito aquém 
do que os GLBT demandam em termos de direitos e de cidadania (MONTEIRO, 1996), o que inclui acesso à educação de qualidade, à adoção e possibilidade de formação de uma família com prole e via casamento. Mas, como bem salientam Pedroso (2003) e Simonian (2004), a sociedade e os GLBT são incansáveis na perspectiva de consolidarem seus objetivos, como se pode encontrar no meio rural e mesmo em cidades do interior da Amazônia.

$\mathrm{Na}$ Argentina, e neste mesmo ano, avanços mais significativos ocorreram no que diz respeito aos interesses e aos direitos GLBT. Como posto por Scarelli (2010), a aprovação pelo senado desse país do casamento civil certamente pode resultar em uma pressão quando ao Estado brasileiro. Essa lei foi efetivamente aprovada na madrugada do dia 15 de julho de 2010, o que no entendimento de Mikevis (2010), terá implicações para o Brasil e, quiçá, para toda a América Latina, e isso muito em função de sua formação social que tem na religião e em padrões conservadores alguns de seus fundamentos mais importantes.

Tais mudanças e impasses terão, por certo, desdobramentos na cultura escolar, tanto no sentido da percepção e da atuação de GLBT que são pais, professores, filhos, irmãos, alunos etc., o que também se remete à relação escola e família. A criação e implantação da Coordenadoria podem vir a contribuir no sentido de incentivar a relação escola e família e assim incentivar a continuidade dos estudos por parte dos GLBT. Com isso, ganharão os GLBT, suas famílias e o próprio Estado, tanto no âmbito federal, estadual como municipal.

\section{Discussão e notas conclusivas}

No que concerne à relação homossexualidade/educação, a realidade é plena de contradições e isto em âmbito mundial, incluindo as áreas usualmente denominadas de primeiro mundo. De todo modo, pesquisas diversas revelam que na medida em que avançam os degraus da educação formal, os GLBT conseguem se inserir em nichos de trabalho mais sofisticados e inclusive com salários altos. E, de acordo com Costa (2002) e Lukenbill (1999), se constituem em consumidores de bens e serviços de padrão elevado, alguns dos quais diferenciados no sentido do atendimento de suas demandas específicas, a exemplo do turismo gay.

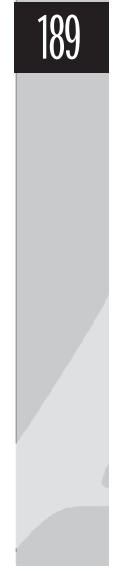


Note-se, no entanto, que mesmo nessas mesmas áreas do capitalismo avançado, nos guetos sociais ali existentes, os GLBT vivem em condições bem diversas, as quais são marcadas pela pobreza, pela violência e pelo uso de drogas. Nestas áreas, tem-se também o preconceito exacerbado, principalmente contra gays negros, indígenas, latinos e asiáticos e em especial contra travestis (SIMONIAN, 2002, 1993-1988). Assim, não raro nas metrópoles do chamado primeiro mundo, violências de toda ordem ocorrem contra tais cidadãos e/ou imigrantes não naturalizados. De todo modo, a perspectiva da afluência socioeconômica dos GLBT já chegou às áreas periféricas do capitalismo mundial, a exemplo do Brasil.

Mas por certo é ainda bastante limitado o poder econômico deste segmento social no país, embora quanto ao movimento de emancipação homossexual, ele se mostra cada vez mais forte. Comojá visto, evidenciouse isto nas conferências estaduais de meados do ano passado e conforme atesta o Relatório (BRASIL, SECRETARIA, 2009) sobre as demandas então apresentadas, discutidas e definidas. Porém, desde então avanços quanto às políticas e às ações públicas vêm se efetivando quanto à relação entre GLBT e educação, e tanto no Brasil como no Pará.

Precisamente, tem-se a campanha iniciada em 29 janeiro de 2009 pela visibilidade das travestis e a portaria n. 016/2008 da SEDUC-PA, vigente desde o dia $1^{\circ}$, desse mesmo mês. Essa última autoriza as escolas a usar em suas práticas educativas os nomes utilizados por travestis e transexuais, o que seguramente vai facilitar o convívio neste locus e a partir dele. No mais, a criação de uma Coordenadoria especializada nessa Secretaria vai possibilitar a consolidação desse processo ora incipiente, mas importante, e que precisa ser consolidado rumo ao reconhecimento do direito a uma educação de qualidade aos GLBT.

No mais, a inspiração decorrente deste processo, e de outros avanços como a possibilidade real de adoção no Brasil e do casamento civil na Argentina, pode vir a contribuir para a produção de um cidadão com possibilidades de um futuro digno e criativo. Essas mudanças recentes e as que ainda estão por vir são importantes para o fortalecimento da identidade GLBT, principalmente quanto à diversidade. Por certo, a garantia do direito a uma educação que implique em formação humana, cidadã e profissional fortalecerá tais cidadãos paraenses, brasileiros e do mundo, com o que ganhará a sociedade mais ampla e o Estado brasileiro, bem como a sociedade internacional. 
A Articulação Nacional de Travestis e Transexuais (ANTRA)... [Versão digital n. p.]. Disponível em: < http://www.acapa.com.br/site/ noticia.asp? codigo $=6994>$. Acesso em: 01/03/2009.

Adoção por casal homossexual, uma notícia boa e outra ruim! 27 abr./2010. 1 fotografia. Disponível em: <http://carlosalexlima.blogspot. com/2010/04/adocao-por-casal-homossexual-uma.html>. Acesso em: nov/2010.

BRASIL. Secretaria Especial de Direitos Humanos. Relatório consolidado das conferencias estaduais de gays, lésbicas, bissexuais, travestis e transsexuais: direitos humanos e políticas púbicas - o caminho para garantir a cidadania de gays, lésbicas, bissexuais, travestis e transsexuais. Brasília: SEDH, 2008.

Constituição da República Federativa do Brasil. Brasília: Senado Federal, 1988.

Casamento gay, sim! Porque contra o amor não há lei. Ilustrado. 19/08/2010. Disponível em: <http://carlosalexlima.blogspot. com/2010/08/casamento-gay-sim.html > . Acesso em: nov/2010.

CARDOSO, F. L. Inversões do papel de gênero: "drag queens", travestismo e transexualismo. Psicologia: Reflexão e Crítica [online]. ISSN 0102-7972. v. 18, n. 3, 2005. pp. 421-430.

COSTA, J. Turismo gay em alta: ponte de ouro no fim do arco-íris. $\mathbf{O}$ Globo. Rio de Janeiro: Caderno Boa Viagem, 2002. pp. 6-17, 2002.

CRUZ, J. I. M. da. A homossexualidade em Santarém: contexto histórico, cultural e reações entre famílias e indivíduos. Trabalho de Conclusão de Curso. 73 f. Belém: IFCH/UFPA, 2002.

Dia da visibilidade das travestis - 29/01/2009. (Versão digital). Disponível em: http://www.athosgls.com.br/noticias_visualiza.php. Acesso em: 01/03/2009.

FERREIRA, R. da S. As "bonecas" da pista no horizonte da cidadania: uma jornada no cotidiano travesti. Belém, 2003. $151 \mathrm{f}$. Dissertação/Mestrado em Planejamento do Desenvolvimento. Belém: NAEA/UFPA, 2003. 
FRY, P. Para inglês ver: identidade e política na cultura brasileira. Rio de Janeiro: Zahar, 1982.

KLAUWITTER, M. M. Gays and lesbians as workers and consumers in the economy. In: RICHARDSON, D.; SEIDMAN, S. (Ed.). Handbook of lesbians and gays studies. London: Sage, 2002. pp. 329-338.

LACERDA, M.; PEREIRA, C.; CAMINO, L. Um estudo sobre o preconceito contra homossexuais na perspectiva das representações sociais. Psicologia: Reflexão e Crítica. ISSN 0102-7972. v. 15, 2002. pp. 165-178.

LUKENBILL, G. Untold millions: secret truths about marketing to gay and lesbian consumers. New York: Harrington Park Press, 1999.

Menina é impedida de estudar porque é gay. O Liberal, Atualidades, p. 4, 28/02/2009. Belém, 2009.

MIKEVIS, D. Casamento gay na Argentina pressiona o Brasil: Senado argentino aprovou lei polêmica na madrugada desta quinta-feira. R7.15jul. 2010, às 17h41m. Disponível em: < http://noticias.r7.com/internacional/ noticias/casamento-gay-na-argentina-pressiona-o-brasil-20100715.html. Acesso em: nov. 2010.

MOTT, L. Etnohistória da homossexualidade na América Latina. Salvador, 2002. (Versão digital n. p.). Disponível em: http://www.geocities. yahoo.com.br/luizmottbr/artigos06.html. Acessado em: 17 set. 2002.

A cena gay de Salvador em tempos de Aids. Salvador: Grupo Gay da Bahia, 2000.

Homo fobia: a violação dos direitos humanos de gays, lésbicas \& travestis no Brasil. Salvador: Grupo Gay da Bahia e..., 1997. 87 p. Ilustrado.

192 [NOVENTA e nove]\% de homofóbicos no país justifica-se por preconceito velado, diz coordenador de pesquisa. (Versão digital n. p.). Disponível em: www.acapa.com.br. Acesso em 12 fev. 2009.

ORGANIZAÇÃO das Nações Unidas - ONU. Declaração Universal dos Direitos Humanos. Adotada e proclamada pela resolução 217 A (III) da Assembléia Geral das Nações Unidas em 10 de dezembro de 1948. (Versão digital n. p.). Disponível em: < http://www.mj.gov.br/sedh/ct/legis intern/ddh_bib_inter_universal.htm >. Acesso em: 01 mar. 2009. 
OROSCO, D. Bandeira do arco-íris. Isto É, São Paulo, n. 1802, p. 7, 1011, 2004.

PARÁ. Emenda Constitucional n. 20, de 17 de junho de 2003. Diária Oficial do Estado do Pará, Belém, 20 de jun. 2003. (Versão digital n. p.). Disponível em: http://www.sefa.pa.gov.br/LEGISLA/leg/Diversa/ ConstEmendas/Emendas/ee00020_03.htm. Acesso em: 13 jan. 2008.

PARKER, R. G. Corpos, prazeres e paixões: a cultura sexual no Brasil contemporâneo. São Paulo: Best Seller, 1991.

PEDROSO, Janari da Silva. Famílias no vale do rio Jari: dinâmicas, mudanças e acomodações. Belém, 2003. 350 f. Tese (Doutorado em Desenvolvimento Sustentável do Trópico Úmido - PDTU)Universidade Federal do Pará.

PLUMMER, K. Telling sexual stories. New York: Routledge, 1995.

SCARELLI, T. C. Votação de casamento gay na Argentina demonstra atraso do Brasil, afirmam ativistas. São Paulo: UOL Notícias, 14 jul. 2010 - 14h58. Disponível em: < http://www.noticias.uol.com.br/ ultimas-noticias/internacional/2010/07/14/votacao-de-casamento-gayna-argentina $>$. Acesso em: nov. 2010.

SCHNNARCH, B. Neither man nor woman: Berdache - a case for non-dichotomous gender construction. Anthropological, Waterloo, v. 34, n. 1, p. 105-121, 1992.

SILVA, H. R. S. Travesti: a invenção do feminino. Rio de Janeiro: RelumeDumará; ISER, 1993.

SIMONIAN, L. T. L. Homosexuality in frontier areas of the Brazilian Amazon. New York/Belém, 2004. Manuscrito.

- Reflexiones sobre la familia en la frontera amazónica: idealizaciones, contradicciones y tendencias actuales. In: TOVAR ROJAS, P. (Org.). Familia, Género y Antropología: desafíos y transformaciones. Bogotá: ICANH, 2003. p. 396-443.

Anotações sobre homossexualidade em Nova Iorque. Nova Iorque, 2000, 1993-1988. Arquivo pessoal. 